\title{
Vehicle fuel consumption prediction based on the data record obtained from an engine control unit
}

\author{
Branislav Sarkan ${ }^{1, *}$, Stefania Semanova ${ }^{1}$, Veronika Harantova ${ }^{1}$, Ondrej Stopka ${ }^{2}$, Maria Chovancova $^{2}$, and Mirosław Szala ${ }^{3}$ \\ ${ }^{1}$ Department of Road and Urban Transport, Faculty of Operation and Economics of Transport and Communications, University of \\ Zilina, Univerzitna 1, 01026 Zilina, Slovak Republic \\ ${ }^{2}$ Department of Transport and Logistics, Faculty of Technology, Institute of Technology and Business in Ceske Budejovice, Okruzni \\ 517/10, 37001 Ceske Budejovice, Czech Republic \\ ${ }^{3}$ Department of Materials Engineering, Faculty of Mechanical Engineering, Lublin University of Technology, Nadbystrzycka 36, \\ 20-618 Lublin, Poland
}

\begin{abstract}
Vehicle fuel consumption is one of the most important operational characteristics of road vehicles. The fuel consumption can be determined by different methods under laboratory conditions or by carrying out drive tests. One of the possibilities to quantify a way of vehicle driving is to analyse the selected parameters of the fuel mixture electronic control system. The objective of the paper is to predict fuel consumption via parameters of throttle position and engine speed. The measurement was carried out in the laboratory of the Department of Road and Urban Transport by using a MAHA roller dynamometer. The result is an estimation of accuracy of such fuel consumption determination and its possible utilisation for a system of assessing the vehicle driving style of drivers.
\end{abstract}

\section{Introduction}

In some cases, recording the electrical course from the selected electronic components of the fuel mixture control system is also an appropriate method to determine fuel consumption. Accuracy of this method depends on a number of factors $[1,2]$. However within laboratory conditions, it can serve as a tool which suitably complements other recorded parameters of fuel consumption. Many foreign studies examine accuracy and dependence between the electrical course of the selected electronic components and fuel consumption. These data can be then used in common vehicle systems that, for example, warn drivers of the wrong driving style in terms of operating fuel consumption $[3,4,5]$. The most commonly used electronic components include the following sensors and actuators:

- throttle position sensor,

- manifold pressure sensor,

- mass air flow sensor,

- crankshaft sensor,

- injection valve,

- idle speed valve.

Dependence of recorded electrical quantities from specific electronic components of the fuel mixture control system on operating fuel consumption differs in terms of a particular vehicle [6]. For this reason, different research tasks are carried out for different vehicles. The example of such dependency is shown in Fig. 1. The parameters as the air flow in the intake system sensed by MAF sensor together with engine load (the value calculated by an engine control unit from several sources - accelerator position, engine speed, manifold pressure and etc.) are evaluated in dependence on the amount of fuel consumed. Their course shows strong linear dependence of different parameters for different vehicles.

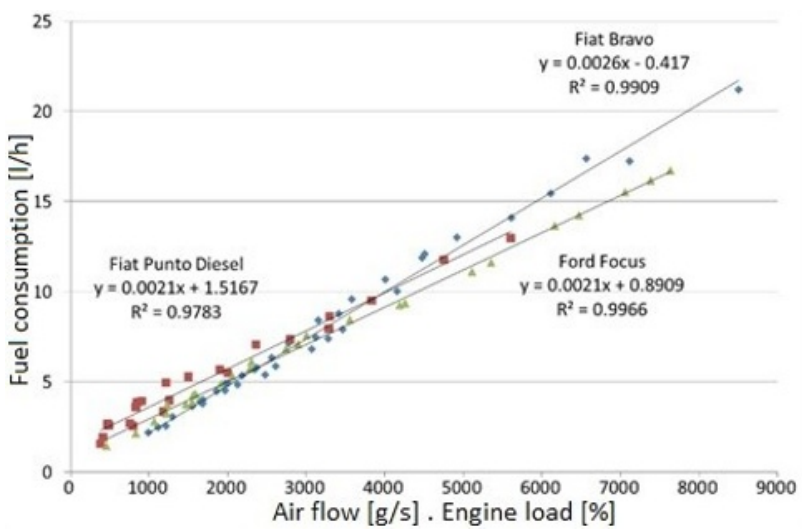

Fig. 1. Dependence of the intake air flow with engine load on fuel consumption [6].

\section{Measurement methodology}

It is the most appropriate to carry out this kind of measurements under laboratory conditions at predefined vehicle driving cycles. The laboratory conditions are also suitable in term of the same climatic conditions throughout whole data recording $[7,8]$. Therefore, the measurement was carried out in the laboratory of the Department of Road and Urban Transport of University of Zilina in Zilina. The drive tests were performed by

* Corresponding author: branislav.sarkan@,fpedas.uniza.sk 
using MAHA MSR 1050 roller dynamometer by using of which the world-wide harmonised WLTP driving cycle was simulated $[9,10]$. Measurement procedure and data acquisition from the control system are shown graphically in Fig. 2. The test was carried out based on the WLTP cycle only in its first part i.e. vehicle driving time of 600 seconds.

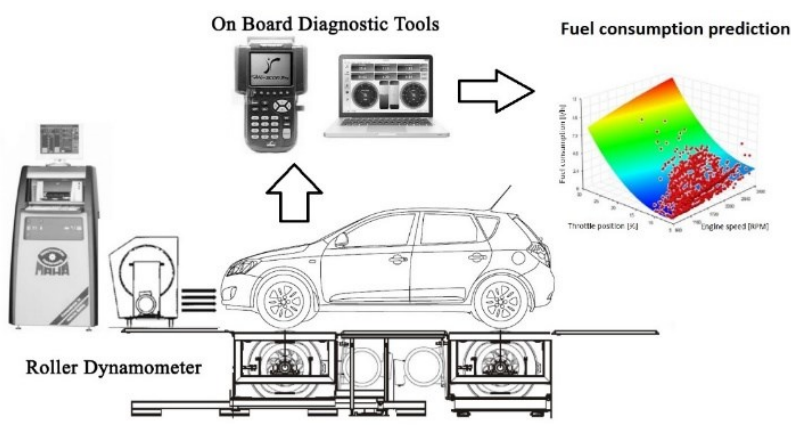

Fig. 2. Scheme of data acquisition and processing.

The measurements were carried out with laboratory vehicle Kia Ceed 1.6 CVVT. The vehicle is equipped with a spark-ignition engine and it has a multi-point indirect injection system (Motronic) with sequential fuel injection.

Recording of the measured data was ensured by using the control computer of the roller dynamometer as well as by reading "live data" from the universal OBD diagnostics with TouchScan software $[11,12,13]$. The measured parameters, which were saved for further processing, included in particular: engine speed, fuel consumption, throttle position and vehicle speed (Fig. 3). The used OBD diagnostics allows recording the selected values at the level of approximately $3 \mathrm{~Hz}$, i.e. in overall 1800 values were recording during the simulated cycle.

\section{Results}

Based on the recorded data on engine speed, throttle position and fuel consumption obtained from OBD diagnostics, the dependency of individual parameters was examined.

Fig. 4 depicts dependence of fuel consumption on engine speed. By adding a trendline to this scatter plot, it was found that a power regression model, shown in the following relationship (1), best suits the given relationship between analysed values. This relationship may significantly predict fuel consumption. In case of the examined vehicle, the engine speed can be a factor that has a significant weight in final fuel consumption $[14,15]$. From this reason, the engine speed is often one of the first parameters that are examined within the evaluation of vehicle driving efficiency.

$$
\text { Fuel consumption }=a \cdot n^{b}
$$

where: $a=0.0005, b=1.0823$

$n$ - engine speed [RPM]
Fig. 5 depicts the scatter of values for the relationship of fuel consumption as the function of throttle opening. The course of a quadratic polynomial best fits the relationship of measured values (as shown in the relationship below). Throttle opening, or accelerator pedal position also significantly influences fuel consumption [16]. The mathematical expression of this dependence is more significant in the case of removing values measured during idle engine speed.

$$
\text { Fuel consumption }=a \cdot x^{2}+b \cdot x+c
$$

where: $\quad a=0.0086, b=0.083, c=0.201$

$x$ - throttle opening [\%]
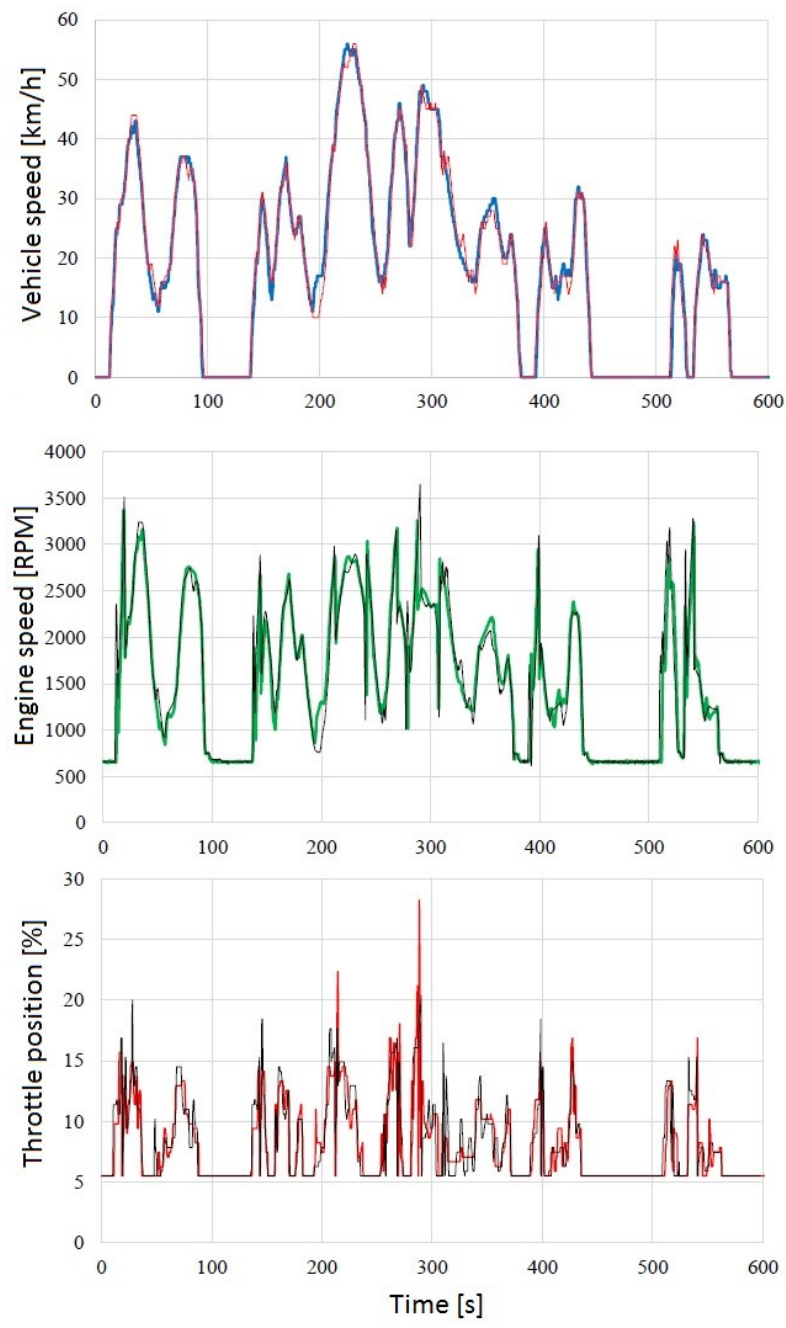

Fig. 3. The recorded course of vehicle speed, engine speed and throttle position.

Eventually, a 3D regression model was derived for fuel consumption in relation to both previous mentioned parameters i.e. throttle position and engine speed (Fig. 6). A linear polynomial model, shown in the following relationship (3), best fits the function of surface regression.

$$
\text { Fuel consumption }=a+b \cdot x+c \cdot n+d \cdot n \cdot x+e \cdot n^{2}+f \cdot x^{2}
$$

where: $\quad a=0.76712, b=-0.25558, c=1.004 \cdot 10^{-3}$,

$$
d=1.95 \cdot 10^{-5}, e=-1.1 \cdot 10^{-7}, f=0.0175
$$




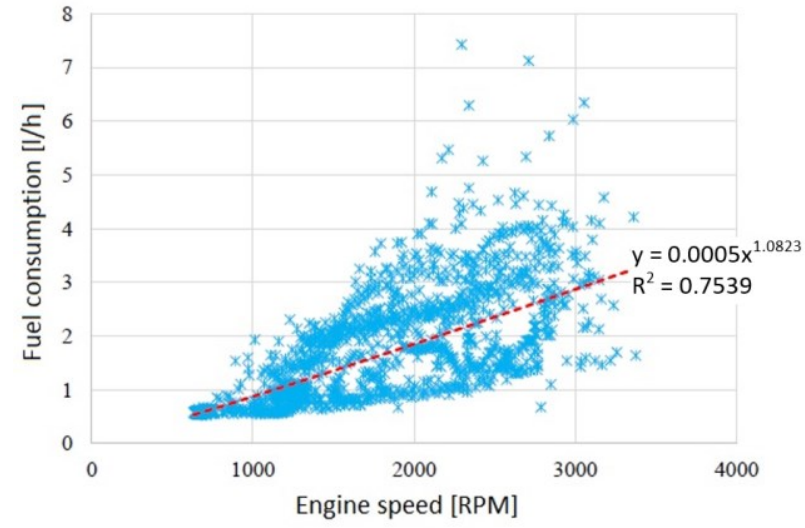

Fig. 4. Dependence of engine speed on fuel consumption.

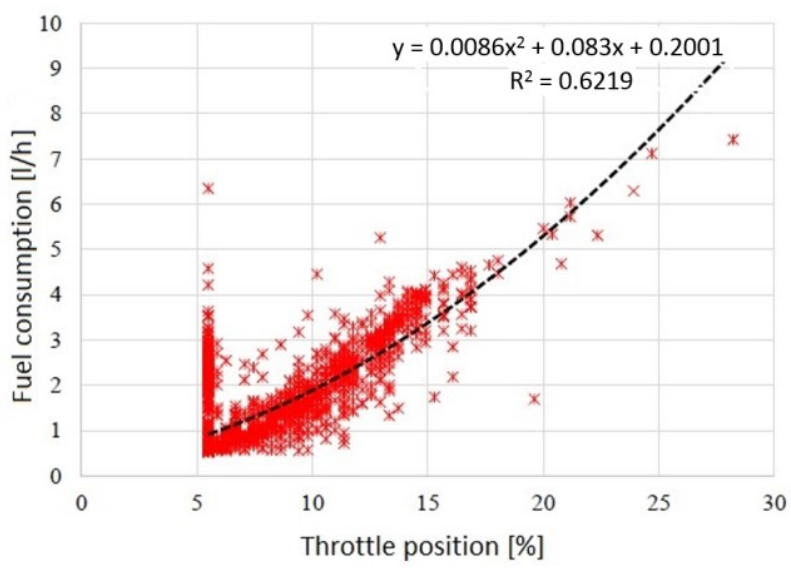

Fig. 5. Dependence of throttle position and fuel consumption.

The coefficients $(\mathrm{a}-\mathrm{f})$ were calculated by using Microsoft Excel and Solver tool. In order to approximate the values of calculated instantaneous consumption data as much as possible to the measured fuel consumption values, several iterations were made till the minimum deviation was accomplished. By successive recalculations, the resulting coefficient values at which the value of instantaneous consumption reached a minimum difference from the measured values were calculated.

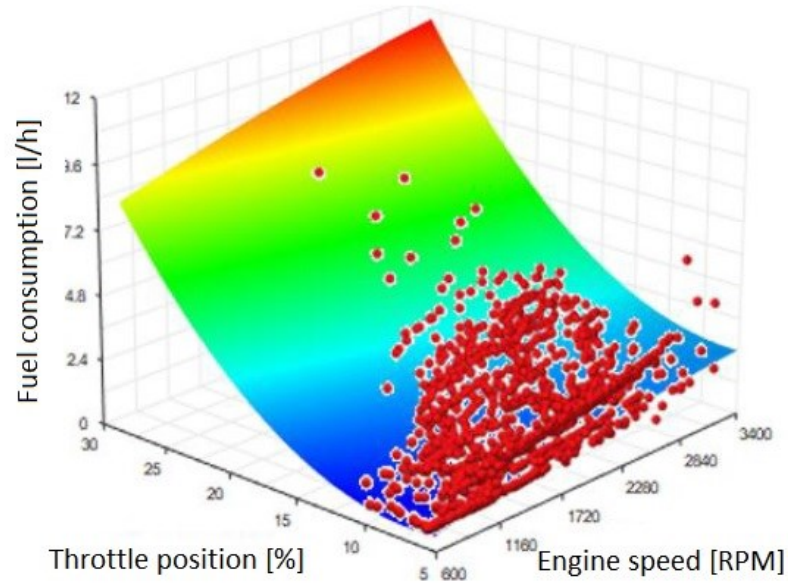

Fig. 6. Dependence of engine speed and throttle position on fuel consumption.

\section{Conclusion}

The mentioned methods of fuel consumption prediction by using the parameters from the fuel mixture control system can be a useful tool when assessing the level of economic drive of drivers $[17,18]$. It was also possible to compare proposed models for the examined vehicle with its real fuel consumption because a flow meter to exactly measure fuel consumption with a variance of 0.5 $\%$ was used during the measurement. During the measurement, fuel consumption recorded by the flow meter was at the level of 1.4921 per hour which represents the average fuel consumption $8.351 / 100 \mathrm{~km}$ considering $3.043 \mathrm{~km}$ of distance travelled. In case of the realization of the fuel consumption estimation by using the 3D model (dependence of engine speed and throttle position on fuel consumption), accuracy of the prediction is $0.228 \%$.

\section{References}

1. M. G. Lee, Y. K. Park, K. K. Jung, J. J. Yoo, International Journal of $u$ - and e-Service, Science and Technology, 4 (2011)

2. T. Skrucany, J. Gnap. Appl Mech Mater, 617: 296301 (2014)

3. Z. Matuszak, M. Jaskiewicz, K. Ludwinek, Z. Gawecki. Special characteristics of reliability for serial mechatronic systems. In: Selected Problems of Electrical Engineering and Electronics (WZEE), Kielce, Poland (2015)

4. D. Barta, M. Mruzek, R. Labudal, T. Skrucany, L. Gardynski, Adv Sci Tech - Research Journal, 12(1): 228-235 (2018)

5. T. Figlus, M. Koziol. J Mech Sci Technol, 30(8): 3567-3576 (2016)

6. A. Alessandrini, F. Filippi, F. Ortenzi. Consumption calculation of vehicles using OBD data. In : 20th International Emission Inventory Conference "Emission Inventories - Meeting the Challenges Posed by Emerging Global, National, and Regional and Local Air Quality Issues", Tampa, Florida (2012)

7. J. Czaban, D. Szpica. Mechanika, 19(5): 600-605 (2013)

8. T. Osipowicz, K. F. Abramek, Z. Matuszak, M. Jaskiewicz, K. A. Ludwinek, P. Lagowski. The Concept of Annular Channels Application on the Spraying Nozzle Needle of Modern Fuel Injector in the Aspect of Combustion Process Improvement. In :11th International Scientific and Technical Conference on Automotive Safety, Casta Papiernicka, Slovakia (2018)

9. MAHA MSR - Technical data (2015) Available at: http://www.maha.de/single-roller-dynamometermsr-1000.htm/

10. UNECE. Global technical regulation No. 15 World harmonized Light vehicles Test Procedure. Available at: 
https://www.unece.org/fileadmin/DAM/trans/main/ wp29/wp29r-1998agr-rules/ECE-TRANS$180 \mathrm{a} 15 \mathrm{e} . \mathrm{pdf}$

11. Homola, s.r.o. AIC 1204 User Manual (printed)

12. J. Yanowitz, M.S. Graboski, L.B.A. Ryan, T.L. Alleman, R.L. McCormick, Environmental Science Technology, 33(2): 209-216 (1999)

13. L. Jedlinski, J. Caban, L. Krzywonos, S. Wierzbicki, F. Brumercik, J Vibroeng, 17(1): 175-187 (2015)

14. M. Vojtíšek, M. Kotek. Estimation of Engine Intake Air Mass Flow Using a Generic Speed-density Method. In: MECCA, 12 (2014)

15. A. Kalasova, P. Faith, J. Mikulski. Telematics Applications, an Important Basis for Improving the
Road Safety. In : 15th International Conference on Transport Systems Telematics (TST), Wroclav, Poland, 531: 292-299 (2015)

16. P. Drozdziel, H. Komsta, L. Krzywonos, Transport Problems, 8(3): 131-138 (2013)

17. A. Kuranc, Eksploatacja i Niezawodnosc Maintenance and Reliability, 17(1): 129-134 (2015)

18. S. Kubikova, A. Kalasova, L. Cernicky. Microscopic simulation of optimal use of communication network. In: Telematics - Support for Transport. TST 2014. Communications in Computer and Information Science, Katowice Ustroń, Poland (2014) 